\title{
A phosphatidylcholine hyaluronic acid chitin- nanofibrils complex for a fast skin remodeling and a rejuvenating look
}

This article was published in the following Dove Press journal:

Clinical, Cosmetic and Investigational Dermatology

19 December 2012

Number of times this article has been viewed

\section{Pierfrancesco Morganti' \\ Paolo Palombo 2 \\ Marco Palombo 3 \\ Giuseppe Fabrizi ${ }^{4}$ \\ Antonio Cardillo ${ }^{5}$ \\ Fabiano Svolacchia ${ }^{5}$ \\ Luis Guevara ${ }^{6}$ \\ Paolo Mezzana ${ }^{7}$}

'Department of Applied Cosmetic Dermatology, University of Naples Federico II, Naples, Italy; ${ }^{2}$ Department of Plastic, Reconstructive and Aesthetic Surgery, Saint Eugenio Hospital, Rome, Italy; ${ }^{3}$ Department of Plastic, Reconstructive and Aesthetic Surgery, CTO Hospital, Rome, Italy; ${ }^{4}$ Department of Dermatology, University of Parma, Parma, Italy; ${ }^{5}$ Centre of Nanoscience, Mavi Sud, Aprilia, Italy; ${ }^{6}$ Hospimedical, Pyrmont, Australia; ${ }^{7}$ IRCCS GB Bietti Eye Foundation, Rome, Italy
Correspondence: Pierfrancesco Morganti 4I Via Innocenzo XI, Rome 00165, Italy Tel +39692862626

Fax +3969281523

Email morganti@iscd.it
Background: The reduction of mortality worldwide has led older individuals to seek intervention modalities to improve their appearance and reverse signs of aging.

Objective: We formulated a medical device as innovative block-polymer nanoparticles based on phosphatidylcholine, hyaluronan, and chitin nanofibrils entrapping amino acids, vitamins, and melatonin.

Methods: Viability and collagen synthesis were controlled on fibroblasts ex vivo culture while adenosine triphosphate production was evaluated on keratinocytes culture. Subjective and objective evaluations were performed in vivo on selected volunteer patients.

Results: In accordance with our previous studies, both the in vitro and in vivo obtained results demonstrate the efficacy of the injected block-polymer nanoparticles in reducing skin wrinkling and ameliorating the signs of aging.

Keywords: antiaging agent, scar correction, stretch marks, signaling molecules, photoaging, biostimulation

\section{Introduction}

Major advances in the medical field have led to a significant increase in life expectancy, with attendant greater efforts being directed towards healthier living and growing concerns about general face and body appearance. ${ }^{1}$ The increasing proportion of women and men interested in skin rejuvenation, influenced in part by the media, has created an enormous demand for so-called antiaging remedies to rejuvenate photodamaged skin in the shortest possible time. Signs of relative skin damage associated with age, such as wrinkling, slackening, and irregular pigmentation, are in fact strongly influenced by environmental factors, particularly lifetime sun exposure. ${ }^{2}$ It has been shown for the normal aging process as well as for photoaging that the induction of reactive oxygen species generates mitochondrial DNA mutations, leading to a defective respiratory chain, especially at the level of the fibroblast cell, and higher production of reactive oxygen species is induced, which, in turn and in a vicious cycle, allows further mitochondrial DNA mutation and mutagenesis, independently of the inducing agent. ${ }^{2,3}$ In addition, the induction of common deletion in human skin fibroblasts is paralleled by a measurable decrease in oxygen consumption as well as by an increase in metalloprotein-1. Many studies have shown, in fact, how the induction of matrix metalloproteinases plays a major role in the pathogenesis of photoaging. ${ }^{4,5}$ Moreover, generation of phosphocreatine, and consequently adenosine triphosphate (ATP), is facilitated when creatine is abundant in cells. Indeed, experimental supplementation of normal human fibroblasts with creatine normalizes mitochondrial mutagenesis, as 
well as the functional parameters of oxygen consumption and metalloprotein- 1 production. ${ }^{6}$

As a consequence of all these cellular disturbances, aged skin displays an array of fine, superficial facial lines that leads to the formation of deep creases over the forehead and between the eyebrows, periorbitally, and in the nasolabial folds. This has been shown to be due to an altered skin antioxidant network and a decreased epidermal turnover, with a decline in synthesis and secretion of lipids, signaling-peptide molecules, and their receptors..$^{7-10}$

During the past few years, many different techniques for rejuvenation have been proposed. Among them, injections with fillers and biostimulating agents are used for wrinkle treatment, correction of scars, and soft-tissue augmentation. Increased demand from plastic surgeons for new active medical devices and procedures is accompanied by the increased use of cosmeceuticals and nutricosmetics to obtain beauty and wellness on the inside and outside. ${ }^{11}$

\section{Project}

Drawing on the experience of our group in the use of topical cosmetics $^{12-14}$ and noninvasive procedures adopted to ameliorate the appearance of aging skin, ${ }^{15}$ we developed and studied a new medical device to treat facial lines and body contour by balancing skin cell turnover and metabolism.

This product was formulated to increase, accelerate, and ameliorate the activity of both antiaging cosmetics and injected temporary or permanent fillers, which are predominantly based on the use of collagen and hyaluronic acid. ${ }^{16,17}$ Naturally, the product had to be safe, biocompatible, and stable at the implantation site, with minimal complications and no risk of migration. ${ }^{18}$ We formulated block-polymer nanoparticles (BPN) of phosphatidylcholine linoleic acidrich nanocomplexed with hyaluronan and chitin nanofibrils (PHHYCN) encapsulating cholesterol, creatine, caffeine, melatonin, vitamins $\mathrm{E}$ and $\mathrm{C}$, and the amino acids glycine and arginine. The high content in linoleic acid of the phosphatidylcholine used allowed the active BPN to quickly reestablish skin-barrier function. Thus, while the phosphatidylcholinefatty acids of the BPN composition contribute to balancing the disturbed composition and organization of lipids at the level of epidermal keratinocytes and consequently of corneocyte lamellae, the high level of linoleic acid should contribute to reintegrate the reduced level of ceramide 1 , structural and stabilizing component of the stratum corneum. ${ }^{19,20}$

Ceramides are considered essential for barrier function, not only because of their quantitative significance but also because of their amphiphilic structure and long-chain constituent $N$-acyl fatty acids. They may improve and upregulate the synthesis of filaggrin and consequently the production of normal moisturizing factors..$^{21,22}$

Moreover, the encapsulated cholesterol, regulating the hydration state of the skin together with the metabolites of phosphatidylcholine, plays an important role in lipid phase packing and in regulation of skin scaling, binding, and keeping water at the level of the epidermis's cells. ${ }^{23-31}$ All these activities are modulated and increased by the chitin nanofibrils $(\mathrm{CN})$ encapsulation methodology. ${ }^{32-35}$

Finally, the presence in the formulation of creatine is of primary importance in normalizing mitochondrial activity. In addition, melatonin and vitamins $\mathrm{C}$ and $\mathrm{E}$ are useful components to reintegrate the skin antioxidant network, while glycine and arginine support collagen and elastine synthesis. Also, caffeine has a role in ameliorating cellular tone, its metabolic process, and intercellular signals, according to the recently proposed Nervous Immune Cutaneous Endocrine (NICE) systems concept. ${ }^{36-41}$

\section{Aim}

The aim of the study was to evaluate the rejuvenation effects of injectable active BPN, entrapping the selected active ingredients, on subjects affected by photoaging. In vitro, the activity of this BPN was observed on cultures of stressed keratinocytes and fibroblasts, as well as their ATP and collagen synthesis verified in presence of our product. In vivo, the safety and efficacy of the product to reduce the global appearance of fine, deep lines was established. This innovative nanovehicle based on PHHYCN traps all the active ingredients, allowing their slow release at cell level. ${ }^{32-34}$

\section{Material and methods \\ Formulation}

Eachmillilitercontained: hyaluronan salt $1 \mathrm{mg}$, phosphatidylcholine $3 \mathrm{mg}$, creatine $0.1 \mathrm{mg}$, caffeine $0.1 \mathrm{mg}$, ascorbyl tetraisopalmitate $0.5 \mathrm{mg}$, vitamin E $10 \mathrm{mg}$, chitin nanofibrils $1 \mathrm{mg}$, melatonin $0.1 \mathrm{mg}$, glucosamine $0.1 \mathrm{mg}$, glycine $0.1 \mathrm{mg}$, arginine $0.1 \mathrm{mg}$, sodium phosphate dibasic $2 \mathrm{mg}$, potassium dihydrogen phosphate $0.2 \mathrm{mg}$, sodium chloride $9 \mathrm{mg}$, sterile water for injection to $1 \mathrm{ml}$.

\section{Patient enrollment}

Before the study, each subject was informed about the purpose of the study, and their written informed consent was obtained according to the ethics of medical-device experimentation. No drugs or cosmetic procedures affecting the course of the antiaging treatment were allowed 2 weeks prior to the study period. 
All the 36 volunteer women (age range 30-55 years) between February and April 2011 attended the dermatology outpatient office, as per Lever et al..$^{42}$ The only criterion for entry in the study was the presence of one or more signs of photoaging affecting the face, such as fine wrinkling around the eyes, crease lines around the mouth and cheeks, telangiectasia, wrinkling and spots on the back of the hands, etc, corresponding to degrees 3-5 of the photodigital scale described by Larnier et $\mathrm{al}^{43}$ and previously used by our group..$^{44,45}$

\section{In vitro studies}

Skin aging causes a general reduction of the synthesis of collagen fibres, slowing also keratinocyte turnover and ATP activity. One month before the in vivo intradermal injections the formulation was applied on control ex vivo cultures of fibroblasts and keratinocytes obtained by explants $(8 \mathrm{~mm}$ diameter) of the abdominal skin of the volunteers. Thus the collagen production of the fibroblasts as well as the ATP produced from the keratinocytes' cultures were controlled for, in accordance with the methodologies used in our previous study. ${ }^{35}$

\section{Fibroblast activity}

According to our previous study ${ }^{35}$, viability and proliferation of fibroblasts, isolated from the patients' explant were controlled. They were cultured in 9BM medium (Cambrex MD, USA) at $37^{\circ} \mathrm{C}$ and $5 \% \mathrm{CO} 2$ at $50 \%$ relative humidity (RH).
For four cultures of fibroblasts, $10 \mu \mathrm{g} / \mathrm{mL}$ of the BPN was added; the other four cultures served as controls. Results are reported in Figure 1, illustrating the percentage media of cell proliferation with respect to control values.

\section{Collagen synthesis}

As in our previous study, ${ }^{35}$ the rate of collagen type- 1 synthesis was measured by the use of specific antibodies (enzyme-linked immunosorbent assay) on eight cell cultures, four of which were enriched with $10 \mu \mathrm{g} / \mathrm{mL}$ of the product directly introduced in the culture medium. Four served as nontreated controls. Measurements were done after 6 days of incubation. Results are reported in Figure 2, illustrating the percentage media of collagen increase with respect to the control value.

\section{ATP activity of keratinocytes}

As in our previous study, ${ }^{35}$ the ATP activity was controlled on keratinocyte cultures irradiated by $4 \mathrm{~J} / \mathrm{cm}^{2} \mathrm{UVA}+0.4 \mathrm{Jcm}^{2}$ UVB. Irradiation causes a strong reduction of ATP present and it is dose dependent. Of the twelve dish cultures used, four received $10 \mu \mathrm{g} / \mathrm{mL}$ of the product 24 hours before UV irradiation, whereas eight served as controls (four nonirradiated and four irradiated). The ATP level was detected using ATP Lite-M (Chemioluminescent kit; Packard Bioscience, Groningen, Netherlands). The obtained results are reported in Figure 3, illustrating the percentage media

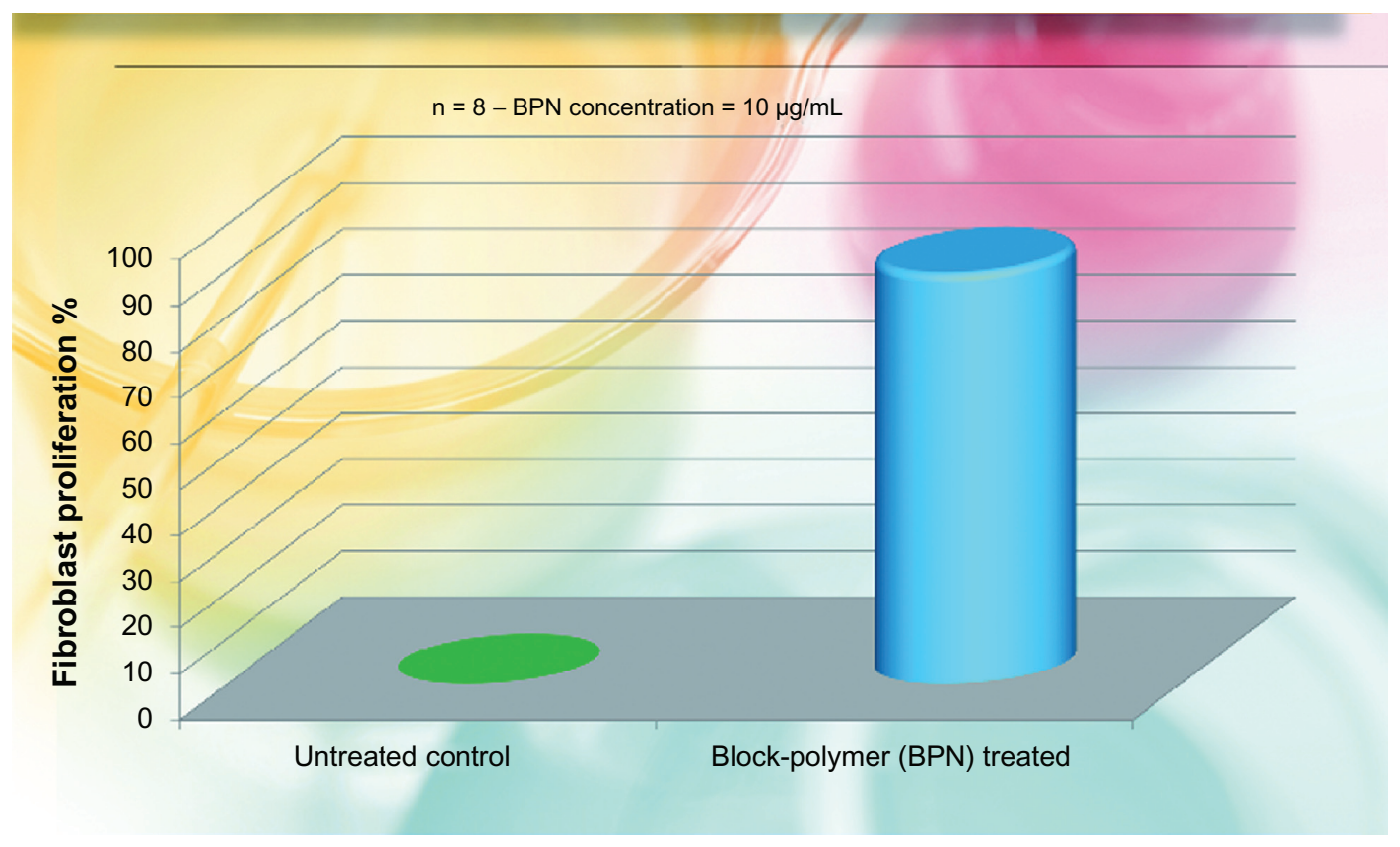

Figure I Fibroblast proliferation recovered by the use of the liposomial complex of phosphatidilcholine-hyaluronic acid-chitin nanofibrils encapsulating active compounds (BPN) vs the untreated control.

Note: BPN values vs control highly significant $(P<0.00$ I $)$. 


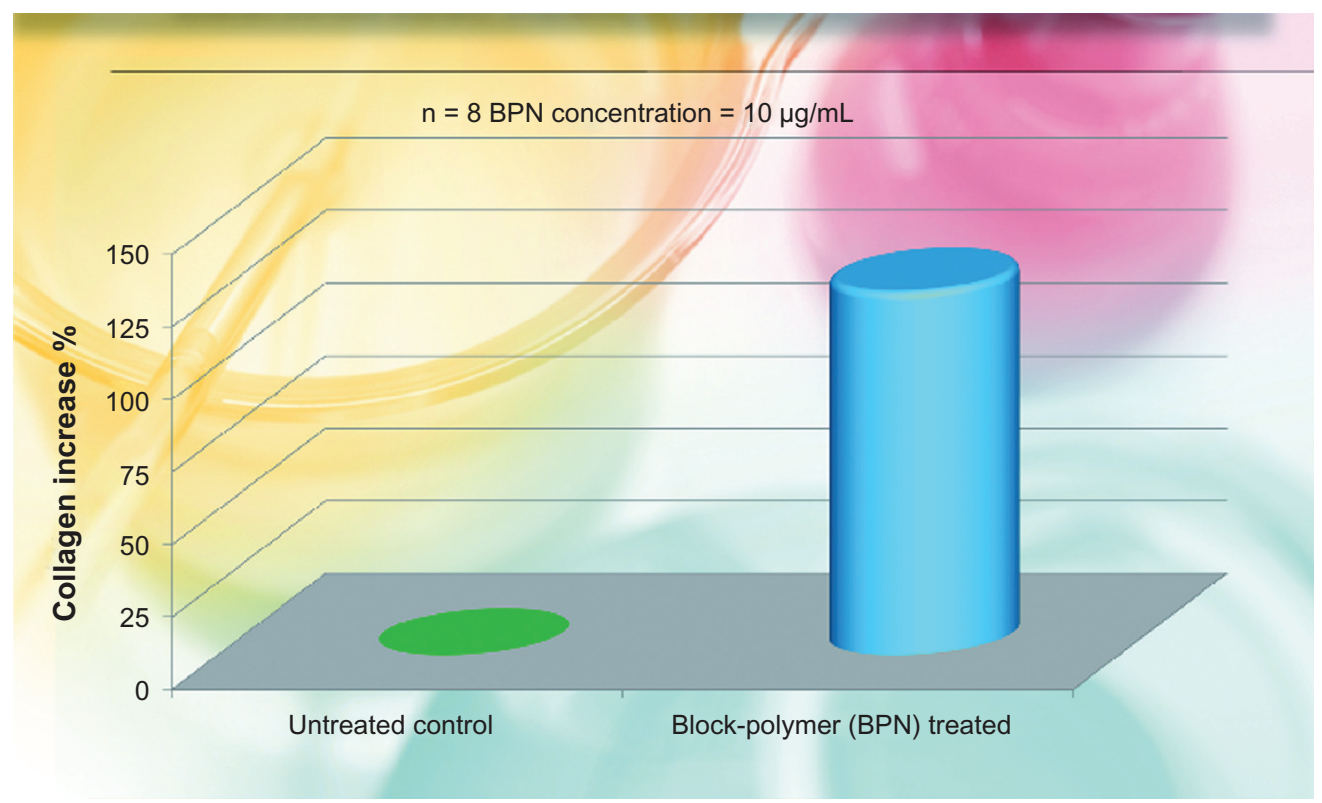

Figure 2 Percent increase of collagen produced by fibroblast cultures added with the liposomial complex of phosphatidilcholine-hyaluronic acid-chitin nanofibrils encapsulating active compounds (BPN) vs the untreated control.

Note: BPN values vs control highly significant $(P<0.00 \mathrm{I})$

of ATP increase with respect to the baseline nonirradiated untreated values.

\section{In vivo studies}

\section{Patient enrollment}

The possibility of having a unique product composed of different kinds of active ingredients with different pharmacological activities at different cell levels would help the operator to obtain the best rejuvenation results from the skin biostimulation.

\section{Injection technique}

The active BPN was injected directly in different skin areas of the 36 women subjects, mean age 51.3 years. The puncture technique used was based on a single injection every 7 days

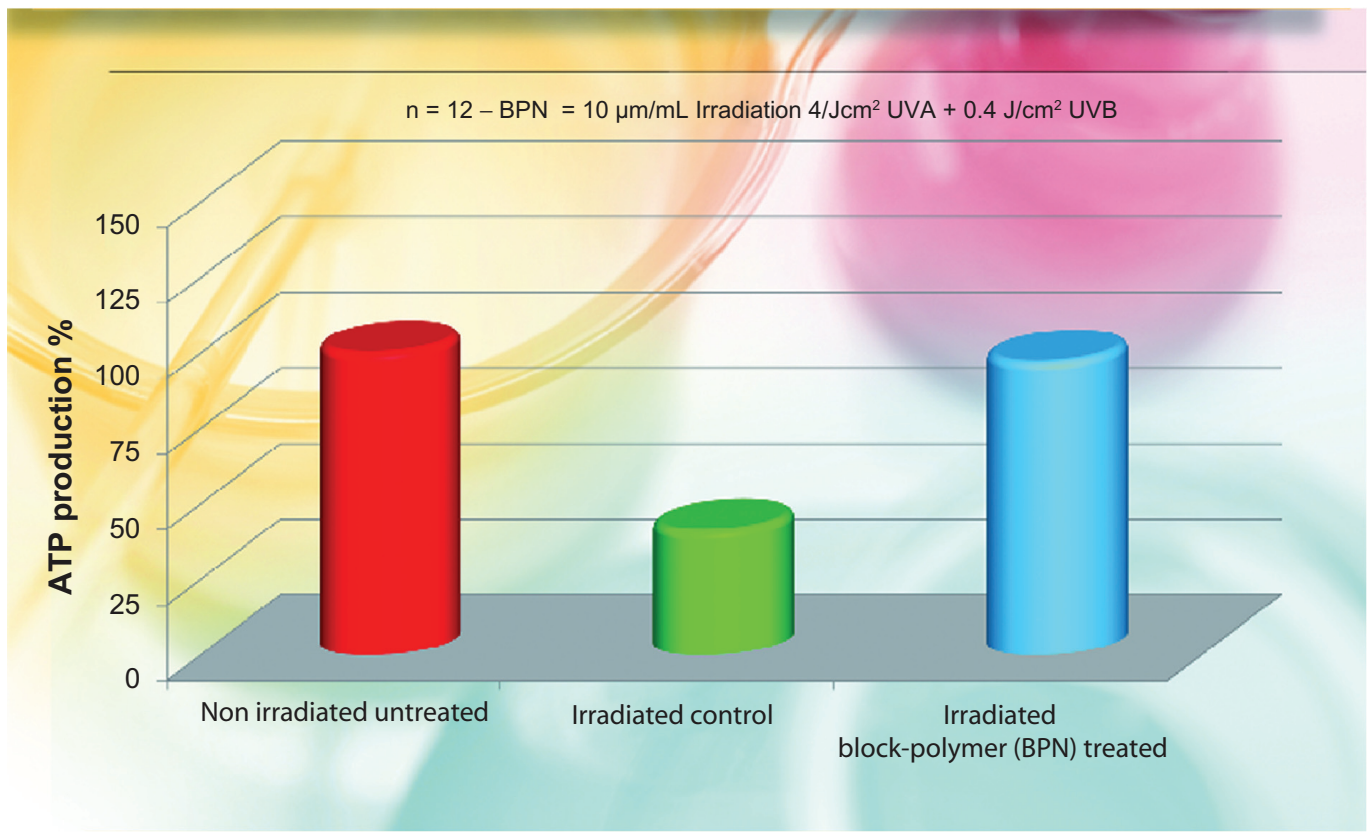

Figure 3 Percent increase of ATP produced by irradiated keratinocyte cultures added with the liposomial complex of phosphatidilcholine-hyaluronic acid-chitin nanofibrils encapsulating active compounds (BPN) vs the untreated control.

Note: BPN vs irradiated and non irradiated control highly significant $(P<0.005)$

Abbreviations: ATP, adenosine triphosphate; UVA, ultraviolet A. 
for 10 weeks, followed by other injections for a further 2 weeks for a global personalized treatment of 90 days with a final control at day 120 (regression period).

The treatment used was based on the mesotherapy technique, using $1 \mathrm{~mL}$ solution and a $30 \mathrm{~g}$ needle positioned at $45^{\circ}$ to the skin surface. The needle was advanced until the middle to deep subcutis, aspiration was performed to ensure that the tip was not within a blood vessel, and injection was then commenced slowly as the needle was withdrawn. Injection rate was at all times less than $0.3 \mathrm{~mL} / \mathrm{min}$. Firm massage, with index finger inside the mouth and thumb outside, was then used to remove any unevenness. The $1-\mathrm{mL}$ quantity is sufficient to treat the entire face. For each skin area, $1-2 \mathrm{~mL}$ of the product was used, as per our previous studies. ${ }^{44,45}$

\section{Control assessment and dermatological evaluation}

Control visits and evaluations were undertaken on the first day (D1, baseline) and after 15 (D15), 30 (D30), 45 (D45), 60 (D60), 75 (D75), and 90 (D90) days of treatment, with a follow-up visit at D120 (regression period). The individual signs of photoaging symptoms of skin irritation and the degree of the obtained correction for each treatment and each area were evaluated objectively by an expert dermatologist using a $0-10$ visual analog scale with separate scores for each site of the face ( $0=$ no correction; $5=$ satisfactory correction; $10=$ total correction). The degree of satisfaction with the efficacy of the product was also obtained subjectively by asking the patients if there was any itching, stinging, or burning sensation. The different mean evaluations are reported in Figure 4, with some photographic examples in Figure 5.

\section{Subjects' evaluation}

After the first, second, and third month of treatment, with a follow-up at the fourth month (regression period), the subjects evaluated their satisfaction or dissatisfaction by giving scores on firmness, softness, hydration, and wrinkle appearance, using a scale of 0-4 for each criterion ( $0=$ unsatisfactory; $4=$ satisfactory $)$, as per Berardesca et al. ${ }^{46}$ The obtained results are reported in Figure 6.

\section{Results and discussion}

The obtained results seem to be in line with our expectations for both the in vitro and in vivo evaluations on the efficacy of the treatment. Practically all the subjects treated during the 90-day period reported that they were satisfied with the general aspect of their skin, which appeared softer and more hydrated since the first month of treatment, as shown in Figure 6. In line with their self-evaluation, the appearance of the fine wrinkling was notably reduced and the consequent skin softness and firmness enhanced during the entire treatment period. It is interesting to note that this general amelioration remained during the regression period also, 30 days after the interruption of the treatment. The same results were clinically observed by the dermatologists involved in the study.

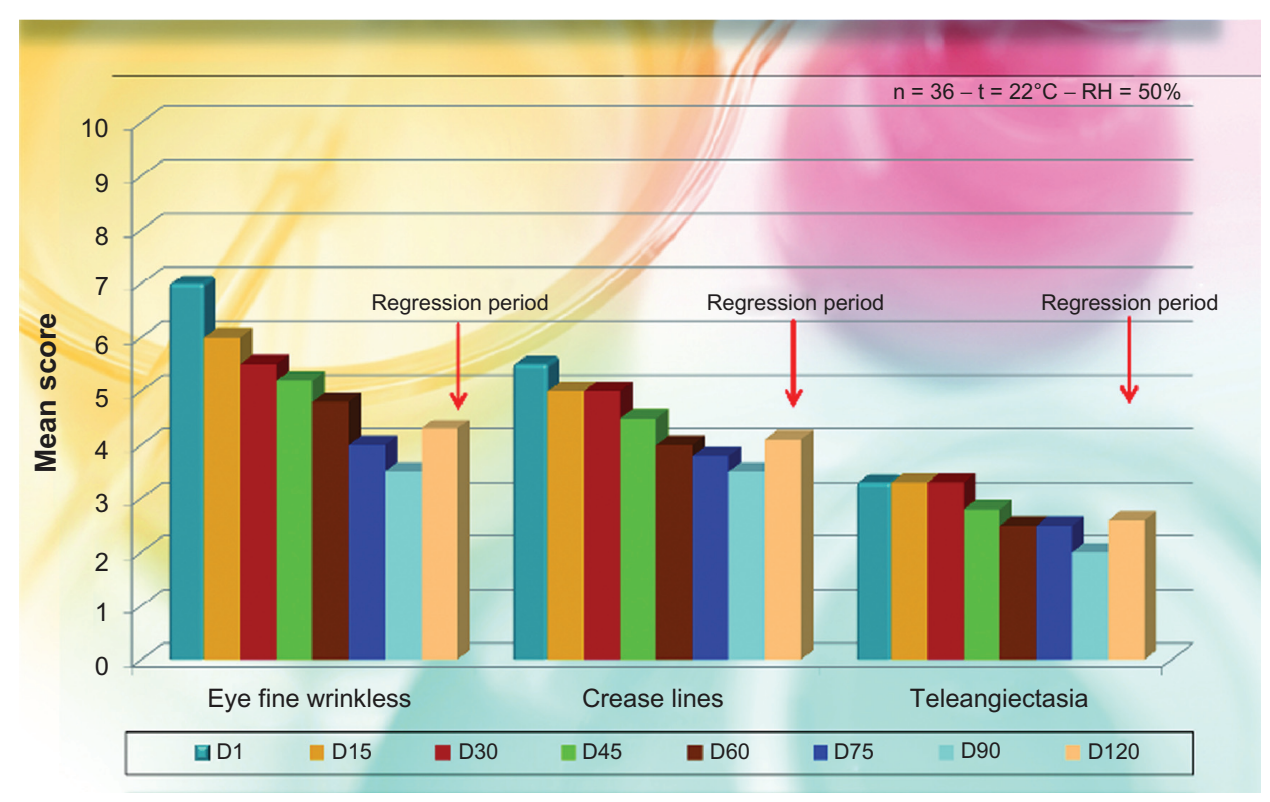

Figure 4 Dermatological mean evaluation on signs of photoageing after injective treatment with phosphatidylcholine-hyaluronic acid-chitin nanofibrils encapsulating active compounds (BPN).

Note: All $P$ values are highly significant as to baseline $(P<0.005)$

Abbreviations: BPN, block-polymer nanoparticles; $\mathrm{RH}$, relative humidity. 

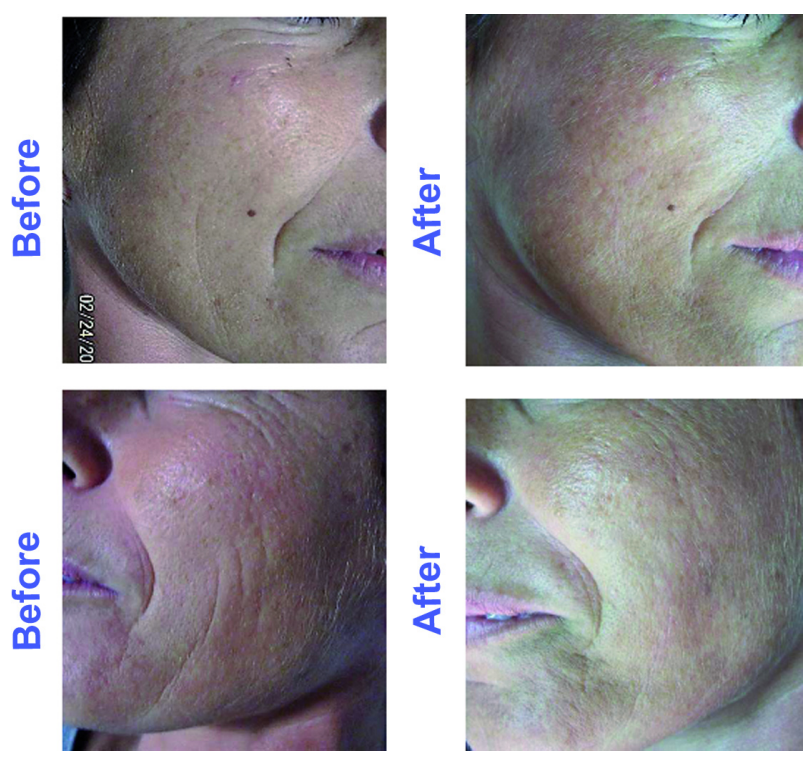

Figure $\mathbf{5}$ View of nasolabial folds and midcheek before (A and $\mathbf{C})$ and after (B and $\mathbf{D}$ ) treatment by the active block-polymer nanoparticles at 30 days.

As shown in Figure 4, both fine wrinkling and crease lines were reduced soon after the first 15 days of treatment, as well as the presence of telangiectasia, so that the general appearance of the face was notably ameliorated during the regression period also. This interesting general amelioration is shown in Figure 5, where a reduction of fine lines is evident.
The in vivo results confirmed the in vitro (ex vivo) studies. As evident from Figure 1, the BPN increased fibroblast proliferation by about $80 \%$ ( $P<0.001)$, along with an increase in collagen production, as shown in Figure 2. Moreover, the increased ATP production of irradiated keratinocytes, has underlined an increased vitality of all the cells involved in daily skin turnover. As shown in Figure 3, the irradiated keratinocytes treated by the use of BPN showed about the same quantity of ATP in comparison with the nonirradiated cultures. From these first results, it is possible to claim that the injectable use of this special formula seems able to stimulate the normal life of all the skin cells of both the epidermis and dermis, improving the general appearance of the face (Figure 5). As previously shown (Figures 1 and 2), both keratinocytes and fibroblasts appear to be able to produce in vitro more ATP and collagen, respectively, so that the final appearance of the skin appears softer and more elastic with reduced numbers of fine wrinkles (Figure 5).

Based on our findings, the BPN encapsulating the active ingredient used, seems to be useful in improving the activity of permanent fillers, rendering it useful as an antiaging remedy for the plastic surgery armamentarium. In conclusion, this innovative biostimulating medical device should be used for wrinkle treatment and rejuvenating looks, as well as an adjuvant in soft-tissue augmentation and stretch-mark corrections.

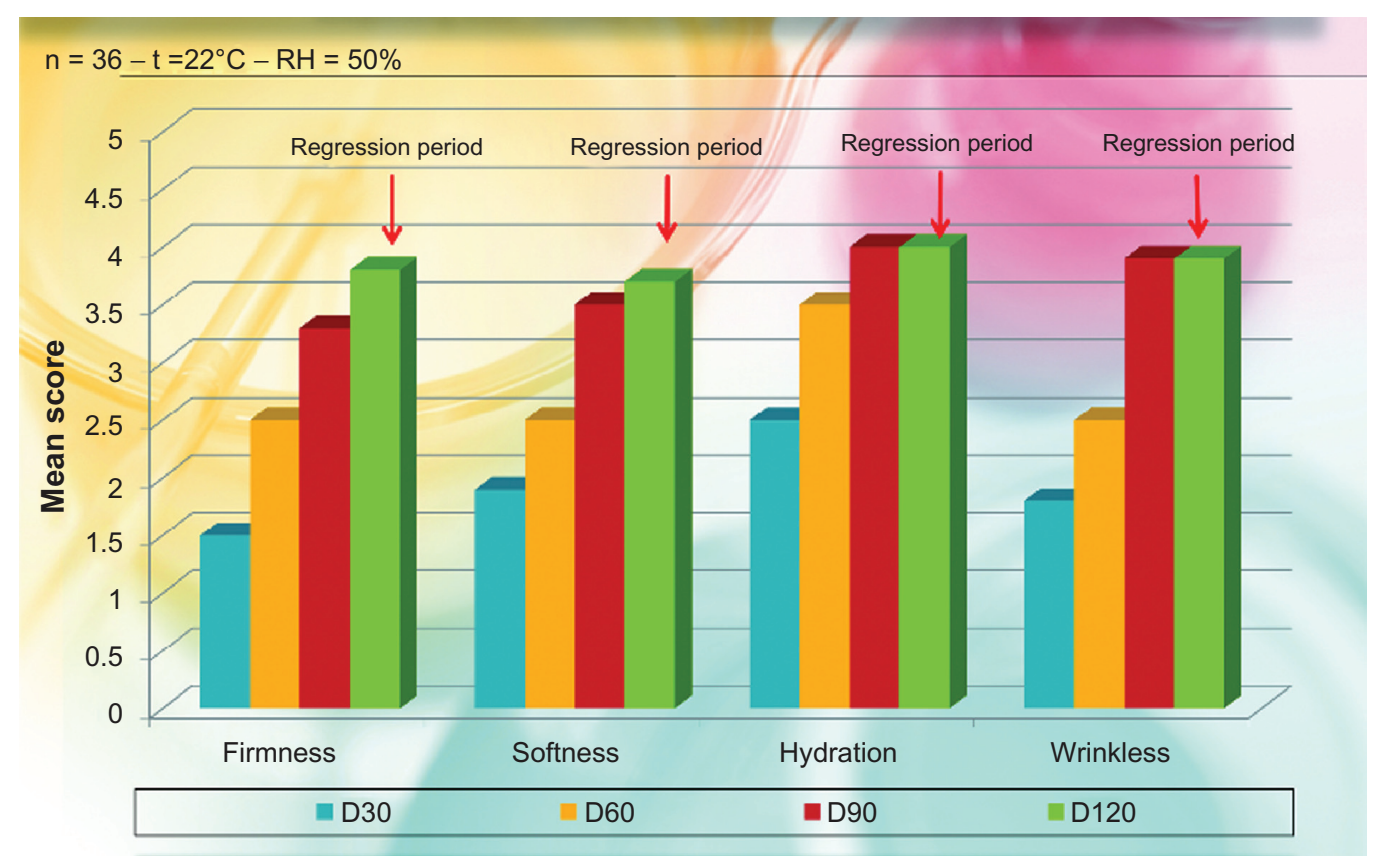

Figure 6 Self evaluation and satisfaction of the subjects treated with phosphatidylcholine-hyaluronic acid-chitin nanofibrils encapsulating active compounds (BPN) (general degree of satisfaction).

Note: All $P$ values are highly significant as to baseline $(P<0.001)$.

Abbreviations: BPN, block-polymer nanoparticles; $\mathrm{RH}$, relative humidity. 
We are continuing with other research for better understanding the mechanism of action of this medical device, and to improve our knowledge on the intimate activity of $\mathrm{CN}$ and $\mathrm{CN}$ complexes as probable signaling molecules at the level of the skin cells.

\section{Disclosure}

The authors report no conflicts of interest in this work.

\section{References}

1. Kramer U, Schikowski T. Recent demographic changes and consequences for dermatology. In: Gilchrest BA, Krutman J, editors. Skin Aging. New York: Springer-Verlag; 2006:1-8.

2. Krutmann J, Gilchrest BA. Photoaging of skin. In: Gilchrest BA, Krutman J, editors. Skin Aging. New York: Springer-Verlag; 2006 33-43.

3. Jacobs HT. The mitochondrial theory of aging: dead or alive? Aging Cell. 2003;2:11-17.

4. Fisher GJ, Wang ZQ, Datta SC, Varani J, Kang S, Voorhees JJ. Pathophysiology of premature skin aging induced by ultraviolet light N.Engl J Med. 1997;337:1419-1428.

5. Schraffeter-Kochanek K, Brenneisen P, Wenk J, et al. Photoaging of the skin from phenotype to mechanisms. Exp Gerontol. 2000;35:307-316.

6. Berneburg M, Gremmel T, Korfen V, et al. Creatine supplementation normalizes mutagenesis of mitochondrial DNA as well as functional consequences. J Invest Dermatol. 2005;125:213-220.

7. Ingram DK, Krutmann J. Age-related decline in physical activity: generalization to nonhumans. Med Sci Sports Exerc. 2000;32: 1623-1629.

8. Peters A. Structural changes that occurs during normal aging of primate cerebral hemispheres. Neurosci Biobehav Rev. 2002;26:733-741.

9. Schatzer WE, Master SL. Age-related changes in vascular adrenergic signaling: clinical and mechanistic implications. Ageing Res Rev. 2003;2:169-190.

10. Morganti P. The cosmetic activity at cell level. Eurocosmetics. 2010; $1-2: 24-26$.

11. Morganti P. Beauty from the inside and the outside. Natural products work in multiple ways. In: Tabor A, Blair R, editors. Nutritional Cosmetics: Beauty from Within. New York: William Andrew; 2009: 95-111.

12. Tucci MG, Mattioli Belmonte M, Muzzarelli R, Ricotti G, Giacchetti A, Biagini G. Prospects for cutaneous wound healing in aged skin. A working hypothesis: chitosan and ceramides. J Appl Cosmetol. 1998;16:51-56.

13. Morganti P, Fabrizi G. Safety evaluation of phytosphingosine and ceramides of pharmaceutical grade. J Appl Cosmetol. 1999;17:1-9.

14. Morganti P, Fabrizi G, James B. A new cosmetic solution for a mild to moderate xerosis. J Appl Cosmetol. 1999;17:86-93.

15. Di Pietro A, Fabrizi G, Giaroli U, Tiberi L, Bruno C, Morganti P. Role of hyaluronic acid and vitamin $\mathrm{C}$ in photoageing. J Appl Cosmetol. 1998;16:125-133.

16. Di Pietro A, Di Santi G. Recovery of skin elasticity and turgor by intradermal injection of HY by the cross-linked technique. G Ital Dermatol Venereol. 2001;34:187-195.

17. Narins RS, Brandt F, Leyden J, Lorenc ZP, Rubin M, Smith S.A randomized, double-blind, multicenter comparison of the efficacy and tolerability of restylane versus Zyplast for the correction of naso-labial folds. Dermatol Surg. 2003;29:588-595.

18. Requena L, Requena C, Christensen L, Zimmerman US, Kutzner H, Cerroni L. Adverse reactions to injectable soft tissue. J Am Acad Dermatol. 2011;64:1-34.
19. Marenkov LN, Steinert PM. Ceramides are bound to structural proteins of the human foreskin epidermal cornified envelope. J Biol Chem. 1998;273:17763-17770.

20. Uchida Y, Hamonaka S. Stratum corneum ceramides: function, origins, and therapeutic implications. In: Elias PM, Feingold KR, editors. Skin Barrier. New York: Taylor and Francis; 2006:43-64.

21. Holleran WM, Man MQ, Gao WN, et al. Sphingolipids are required for mammalian epidermal barrier function. Inhibition of sphingolipid synthesis delays barrier recovery after acute perturbation. J Clin Invest. 1999;88:1338-1345.

22. McGrath JA, Uitto J. The filaggrin story. Novel insights into skin barrier function and disease. Trends Mol Med. 2008;14:20-27.

23. Norlen L. Skin barrier formulation: the membrane folding model. J Invest Dermatol. 2001;117:823-829.

24. Rawlings AV, Scott IR, Harding CR, Bowser PA. Stratum corneum moisturization at the molecular level. J Invest Dermatol. 1994;103: 731-740.

25. Rawlings AV, Harding CR. Moisturization and skin barrier function. Dermatol Ther. 2004;17:43-48.

26. Ghyczy M, Vacata V. Phosphatidylcholine and skin hydration. In: Leyden JL, Rawlings AV, editors. Skin Moisturization. New York: Marcel Dekker; 2002:303-321.

27. Morganti P, Randazzo SD, Giardina A, Bruno C, Vincenti L, Tiberi L. Effects of phosphatidylcholine linoleic acid-rich and glicoli acid in acne vulgaris. J Appl Cosmetol. 1997;15:21-41.

28. Morganti P, Agostini A, Bruno C, Fabrizi G. Role of topical glicolic acid and phosphatidylcholine linoleic acid in the pathogenesis of acne. Linoleic avid vs squalene. J Appl Cosmetol. 1997;15:33-41.

29. Morganti P, Morganti G. Chitin nanofibrils for advanced cosmeceuticals Clin Dermatol. 2008;26:334-340.

30. Morganti P, Morganti G, Fabrizi G, Cardillo A. A new sun to rejuvenate the skin. J Appl Cosmetol. 2008;26:159-168.

31. Morganti P. Chitin nanofibrils for cosmetic delivery. Cosmet Toil. 2010;125:36-39.

32. Morganti P. Chitin nanofibrils and their derivatives as cosmeceuticals. In: Kim SK, editor. Chitin, Chitosan, Oligosaccharides and Their Derivatives: Biological Activities and Application. New York: CRC Press; 2010:531-542.

33. Morganti P, del Ciotto P, Morganti G, Fabien-Soulé V. Application of chitin nanofibrils and collagen of marine origin as bioactive ingredients. In: Kim SK, editor. Marine Cosmeceuticals: Latest Trends and Prospects. New York: CRC Press; 2011:267-290.

34. Morganti P, Fabrizi G, Palombo M, Guarneri F, Cardillo A, Morganti G. New chitin complexes and their anti-aging activity from inside out J Nutr Health Aging. 2012;16(3):242-245.

35. Morganti P, Palombo M, Palombo P, et al. Cosmetic science in skin aging: achieving the efficacy by the chitin nano-strucured chrystallites. SOFW J. 2010;136:14-24.

36. Pert C, Ruff M, Weber R, Herkenam M. Neuropeptides and their receptors: a psychosomatic network. J Immunol. 1985;135:820-826.

37. Torii H, Yan Z, Hosoi J, Granstein RD. Expression of neutrophic factors and neuropeptide receptors by Langerhans cells and the Langerhans cell-like line XS52: further support for a functional relationship between Langerhans cels and epidermal nerves. J Invest Dermatol. 1997;109:586-591.

38. Maynard SJ, Szathmary F. The Origins of Life: From the Birth of Life to the Origin of Language. New York: Oxford University Press; 1999.

39. Morganti P, Li YH, Chen HD. NICE melody for innovative mind-body skin care. Cosmet Sci Technol. 2011;21:49-59.

40. Morganti P, Chen HD. Skin cell management: the NICE approach. Personal Care. 2011;4:29-36.

41. Morganti P, Chen Hong Duo. Skin cell management: more than a cosmetic approach. The Biomedical Scientist. 2011;55:460-464.

42. Lever L, Kumar P, Marks R. Topical retinoic acid for treatment of solar damage. Br J Dermatol. 1990;122:91-98. 
43. Larnier C, Ortonne JP, Venot A, et al. Evaluation of cutaneous photodamage using a photographic scale. Br J Dermatol. 1994;130: 167-173.

44. Di Pietro A, Fabrizi G, Giaroli U, Tiberi L, Bruno C, Morganti P. Role of hyaluronic acid and vitamin $\mathrm{C}$ in photoageing. J Appl Cosmetol. 1998;16:125-133.
45. Morganti P, Palombo P, Fabrizi G, Palombo M, Persechino S. Biweekly in-office injectable treatment of striae distensae vs a long-term daily use of topical vitamin C. J Appl Cosmetol. 2001;19:107-112.

46. Berardesca E, Distante F, Anthoine P, Rabbiosi G, Aubert L. Clinical and instrumental evaluation of the activity of an anti-wrinkle product on cutaneous relief and photoaged skin. J Appl Cosmetol. 1997;15:69-75.

\section{Publish your work in this journal}

Clinical, Cosmetic and Investigational Dermatology is an international, peer-reviewed, open access, online journal that focuses on the latest clinical and experimental research in all aspects of skin disease and cosmetic interventions. All areas of dermatology will be covered; contributions will be welcomed from all clinicians and basic science researchers globally. This journal is indexed on CAS

The manuscript management system is completely online and includes a very quick and fair peer-review system, which is all easy to use. Visit http://www.dovepress.com/testimonials.php to read real quotes from published authors.

Submit your manuscript here: http://www.dovepress.com/clinical-cosmetic-and-investigational-dermatology-journal 